\title{
Correction to: Activity recognition through interactive machine learning in a dynamic sensor setting
}

\author{
Agnes Tegen $^{1} \cdot$ Paul Davidsson $^{1} \cdot$ Jan A. Persson ${ }^{1}$ \\ (C) Springer-Verlag London Ltd., part of Springer Nature 2020
}

Correction to: Personal and Ubiquitous Computing https://doi.org/10.1007/s00779-020-01414-2

Fig. 7 and Fig. 8 have incorrect legends in the images and have been updated.
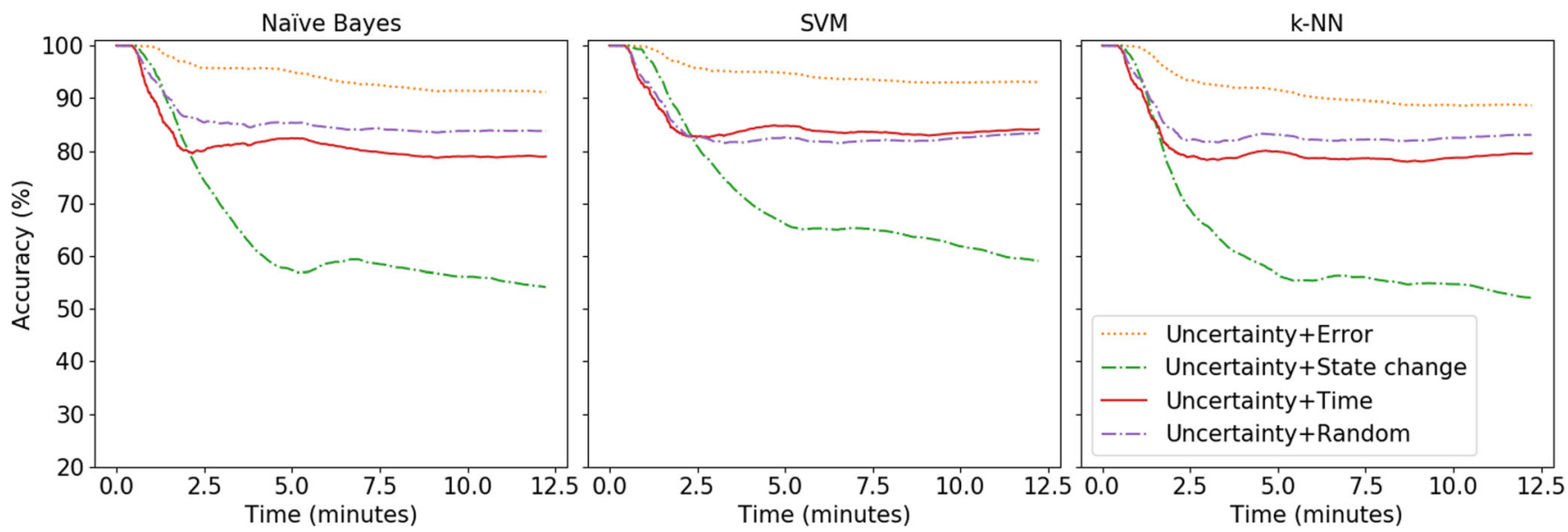

Fig. 7 The accumulated accuracy over time for the hybrid interactive learning strategies on the Opportunity dataset

The online version of the original article can be found at https://doi.org/ 10.1007/s00779-020-01414-2

$\triangle$ Agnes Tegen

agnes.tegen@mau.se

Paul Davidsson

paul.davidsson@mau.se

Jan A. Persson

jan.a.persson@mau.se

1 Internet of Things and People Research Center, Malmö University,

Malmö, Sweden 


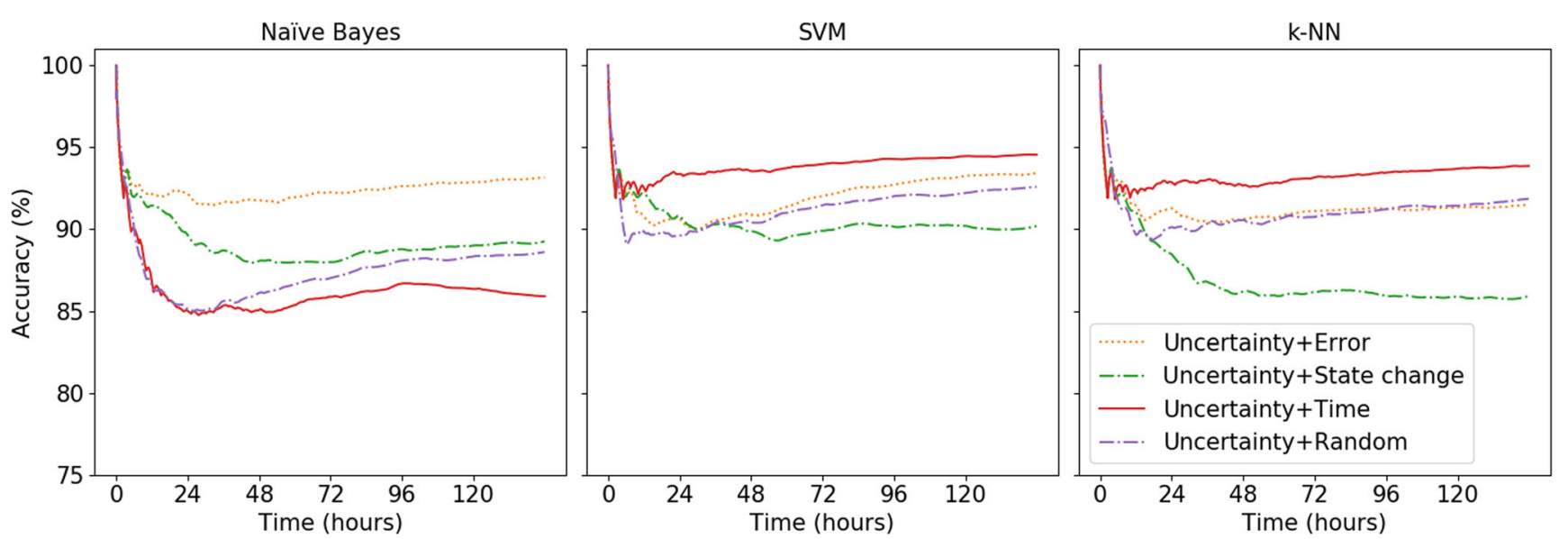

Fig. 8 The accumulated accuracy over time for the hybrid interactive learning strategies on the Occupancy dataset

Publisher's note Springer Nature remains neutral with regard to jurisdictional claims in published maps and institutional affiliations. 